\title{
Performance of driven battered mini-pile group against expansive soil induced ground movement
}

\author{
Shirin Aminzadeh Bostani Taleshani ${ }^{1,}$, Robert Evans ${ }^{1}$, Emad $_{\mathrm{Gad}^{1}}{ }^{1}$, and Mahdi Miri Disfani ${ }^{2}$ \\ ${ }^{1}$ Department of Civil and Construction Engineering, Swinburne University of Technology, Melbourne, Australia \\ ${ }^{2}$ Department of Infrastructure Engineering, The University of Melbourne, Melbourne, Australia
}

\begin{abstract}
Swell-shrink movement of expansive soils due to seasonal wetting and drying can cause differential ground movements. This movement can inflict substantial structural damage above foundation level to lightly loaded infrastructure. To reduce this movement, techniques have been employed to either (i) chemically restrain the soil's reactivity, (ii) control the moisture variation within the ground, or (iii) engage a footing system that can limit the impact of the stresses generated by such differential ground movements. Recently, a new concrete-free footing system has been developed in Australia in an attempt to sufficiently resist such ground movements. This system is comprised of an adjustable steel plate attached to the ground by multiple thin steel (hollow) battered mini-piles. The technology shows promise as a low-impact, cost-effective, excavation and concretefree, innovative alternative to traditional footing systems. It is also quick and easy to install without the use of bulky and expensive equipment. Early field trial results have indicated that this new footing system can combat against and significantly reduce the transfer of the swell-shrink ground movements to a structure. This paper will describe this new footing system and report on an experimental field trial to date, which will include measured ground movements, moisture content and soil suction results vs. depth, as well as the performance of this new driven battered mini-pile group footing system.
\end{abstract}

\section{Introduction}

Swell-shrink movement of expansive soils due to seasonal wetting and drying can cause differential ground movements. This movement can inflict substantial structural damage above foundation level to lightly loaded infrastructure. The first record of damage arising from expansive soils was made in Oregon (USA) and ever since, issues such as stair-step fractures of brick and stone walls, cracked foundations and pavements, uneven floors, and undulating road surfaces, have been reported worldwide [1]. The financial burden of damages associated with construction on expansive soils is beyond the costs inflicted due to floods, hurricanes, tornadoes, and earthquakes combined [2]. Thus, expansive soil deposits are considered a potential natural hazard that can pose problems of enormous financial proportions, in especially in regions with pronounced wet and dry seasons that exacerbate the total ground movement. In Australia, moderate to highly expansive clays prevail in about 20 per cent of the total area with a significant portion of this being inhabited. Furthermore, in many of these regions, the climate consists of wet and dry cycles.

Conventional treatment methods include chemically stabilizing the soil, creating horizontal and/or vertical moisture barriers, and adopting special footing systems, such as shallow reinforced concrete rafts and deep concrete piers. However, they all have the following drawbacks: (i) chemical stabilization is time-consuming and only applicable to the top layers of certain soil types [3], (ii) moisture barriers need to be placed at depths greater than the root zone and are ineffective in cracked soils, tight subgrade soils and semi-arid climates [4], (iii) stiffened rafts appear satisfactory only for sites exhibiting low to moderate expansive potential with a shallow active zone [5], and (iv) pier foundations are prone to tension cracks due to swelling induced tensile forces, deep-seated heave and mushrooming due to reckless construction [6-8]. Accordingly, a demand for alternative techniques capable of reducing expansive soil induced movement more effectively is evident.

To rise to the challenge, a variety of innovative techniques have been devised and the driven battered steel mini-pile group is a recent example manufactured in Australia. This technology shows promise as a lowimpact, cost-effective, excavation and concrete-free alternative to traditional footing systems, allowing the structure to sufficiently resist ground movement. This resistance is believed to be due to the tree root inspired configuration of the system, as shown in Fig. 1, that involves a much larger area to comply with the swell- 
shrink movement. Given that piles are battered, the engaged soil not only can provide skin friction but also can serve as passive and bearing resistance elements to oppose forces generalized from swelling and shrinkage, respectively. Fig. 2 presents a schematic view of the passive and bearing resistance that is postulated to be mobilized along the pile length due to the seasonal ground movement (swelling/shrinkage).

(a)
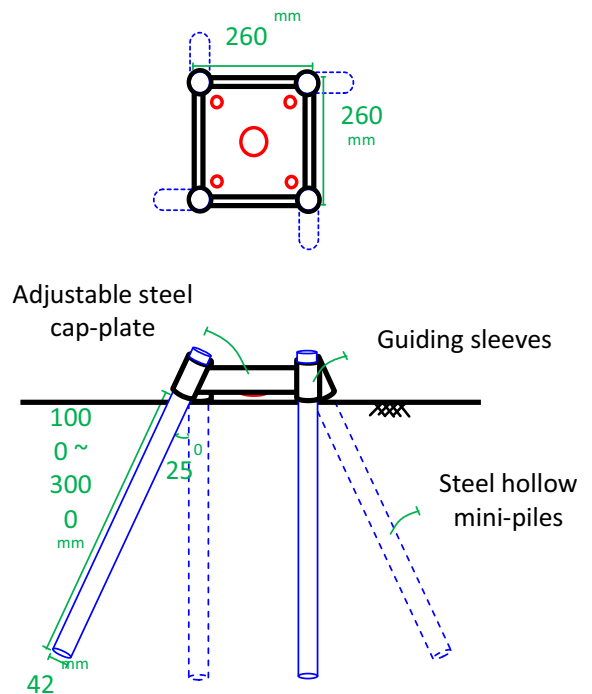

(b)

Fig. 1. Typical configuration of braced battered mini-pile footing: (a) Plan view; (b) Elevation.

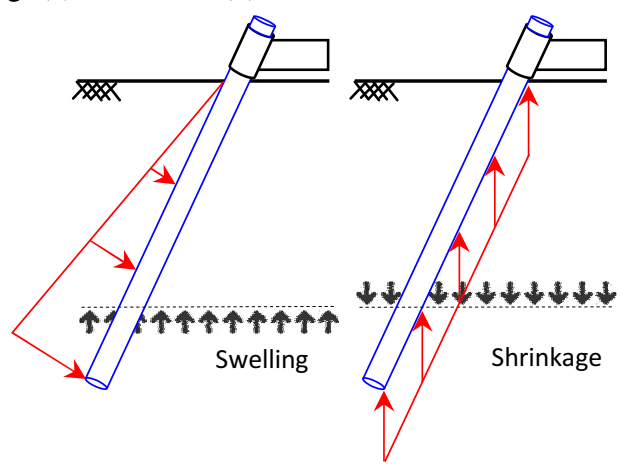

Fig. 2. Resisting passive and bearing forces mobilized against the swelling and shrinkage forces.

This new footing system is composed of multiple thin steel hollow mini-piles attached to an adjustable steel plate through guiding sleeves at different angles. These recyclable galvanized piles of diameter $42 \mathrm{~mm}$ are driven into the ground by hand-held vibratory power tools and typically vary in length between 1 and $3 \mathrm{~m}$. Thus, there is no need to excavate the soil, which result in minimal disturbance to the site and existing structure [9]. The number, length, raking angle, and layout of the mini-piles can vary depending on the required capacity, type of expansive soil (i.e., reactivity) and climatic conditions. Although some pilot studies have been conducted on the bearing capacity of this system [9-11], the mechanism of pile-soil interaction due to expansive soil induced ground movement has yet to be understood. To provide a better understanding of this interaction, a suitable expansive site was instrumented and the performance of this new footing system against the ground movements due to varied moisture content was assessed. Here, we report measured ground movements, moisture content and soil suction results vs. depth, as well as the performance of this new driven battered mini-pile group footing system to date.

\section{Experimental site}

Moderate to highly expansive clays cover a significant part of the surface soils in Victoria [12], particularly the western parts of Melbourne [13]. The clay soils in Melbourne are formed mainly by in-situ weathering of the base rock [14]. Consequently, the properties of these clays are fundamentally related to the underlying rock type and can be uniform over large areas of the same rock deposits [15]. Much of the rock deposits in the Melbourne region are Quaternary Basalts and Silurian Mudstones, as presented in Fig. 3. The Quaternary Basaltic clays are mainly distributed in the western regions and have a higher proportion of damaged structures than the Silurian and Tertiary soils [16]. For this reason, an experimental site in Braybrook, which is a suburb in Melbourne's west (see Fig. 3), was selected for long-term field monitoring. The site is located at a residential property that has a front yard of about $200 \mathrm{~m}^{2}$ covered with grass and surrounded by four deciduous trees. Its drainage is performed through surface runoff and has a small surface gradient.

The range of variation in geotechnical properties of the site is presented in Table 1. The soil profile comprises a shallow layer of silty sand overlying silty clay of basaltic origin. Some grassroots were found in the upper layers and traces of Calcium Carbonate $\left(\mathrm{CaCO}_{3}\right)$ were observed between the depths of 1.1 and $2.5 \mathrm{~m}$. Based on the combined Atterberg limit and particle size determination test results, the activity and swell potential of the soil was classified as being very highly reactive, according to Seed and Lundgren [17], Williams [18]. Values of the shrink-swell index $\left(\mathrm{I}_{\mathrm{ss}}\right)$ were used to determine the site reactivity using the method outlined in the Australian Standard [19] and an H2 class was assigned to the site. Therefore, for the purpose of residential construction, it is likely to experience vertical movements in the order of 60 to 75 $\mathrm{mm}$ over 50 years due to natural moisture variation. In addition to determining the simple percentages of sand, silt, and clay, X-ray diffraction (XRD) analysis was also performed to investigate the clay mineralogy (see

Table 2). The XRD results of the Braybrook soil revealed a consistent mineral composition. It is clear that Quartz is dominant and Montmorillonite is the significant clay mineral present. The high amount of Montmorillonite confirms the high degree of the expansiveness of the soil across the experimental site. These results were confirmed with similar test results at another nearby test site, also in Braybrook [20]. 
Table 1. Range of geotechnical properties of clay at the site.

\begin{tabular}{|c|c|c|c|c|c|}
\hline $\begin{array}{c}\mathrm{LL} \\
(\%)\end{array}$ & $\begin{array}{c}\mathrm{PL} \\
(\%)\end{array}$ & $\begin{array}{c}\mathrm{LS} \\
(\%)\end{array}$ & $\begin{array}{c}\% \\
\text { Fine }\end{array}$ & $\begin{array}{c}\% \\
\text { Clay }\end{array}$ & $\begin{array}{c}\mathrm{I}_{\mathrm{ss}} \\
(\%)\end{array}$ \\
\hline $89-96$ & $28-37$ & $21-23$ & $83-99$ & $47-71$ & $4.5-6.8$ \\
\hline
\end{tabular}

Table 2. Clay mineralogy of the Braybrook soil.

\begin{tabular}{|c|c|c|c|c|}
\hline $\begin{array}{c}\% \\
\text { Quartz }\end{array}$ & $\begin{array}{c}\% \\
\text { Montmorillonite }\end{array}$ & $\begin{array}{c}\% \\
\text { Kaolin }\end{array}$ & $\begin{array}{c}\% \\
\text { Albite }\end{array}$ & $\begin{array}{c}\% \\
\text { other }\end{array}$ \\
\hline $50-61$ & $33-43$ & $2-3$ & 3 & $<2$ \\
\hline
\end{tabular}

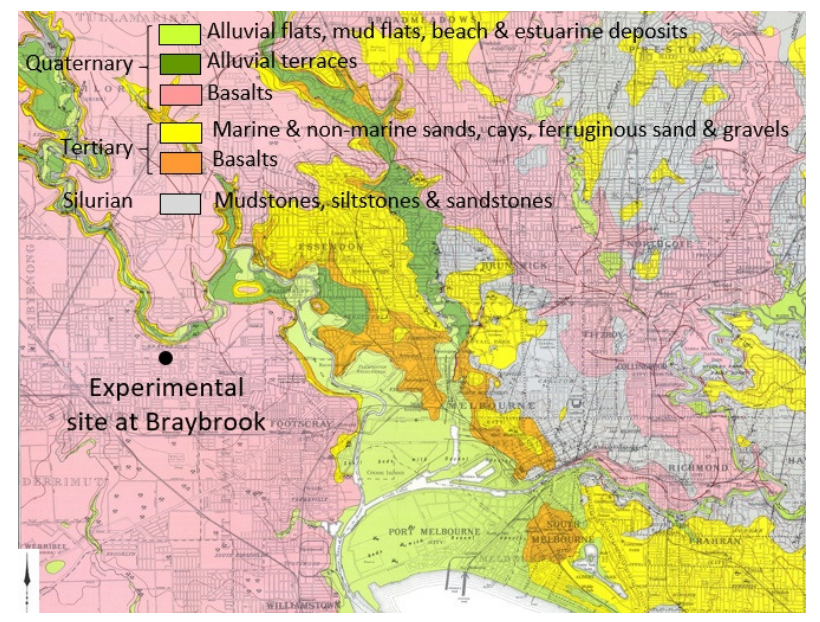

Fig. 3. Geological map of Melbourne and suburbs (Adopted from: Maps - Earth Resources publications [21]).

\section{Site instrumentation}

Site instrumentation was installed to provide data on insitu moisture levels at various depths, ground movement at the surface and depth and the performance of two steel braced mini-piles footing systems at different depths. The layout of the instrumentation is shown in Figure 4. These include: (i) two access tubes, named NP and M.Ex, to measure ground moisture and movement at various depths down to $3 \mathrm{~m}$, which is greater than the expected depth of suction change in the region, (ii) four concrete pavers (CP1, 2, 3 and 4) to record actual ground movement at the surface, and (iii) two footing systems that are identifiable as S250-1200 and S250-1600, both having the same square cap plate $(260 \mathrm{~mm}$ width and 6 $\mathrm{mm}$ thickness) but differing in pile length $(1200 \mathrm{~mm}$ and $1600 \mathrm{~mm}$, respectively).

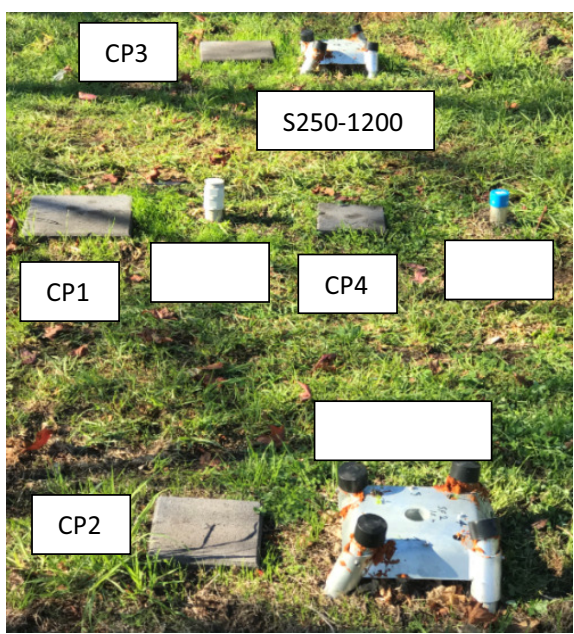

Fig. 4. Site instrumentation at the Braybrook site.

\section{$4 \quad$ Site monitoring}

\subsection{Soil moisture monitoring}

A Neutron Probe type device, which is a non-destructive indirect method of measurement, was selected to measure Volumetric Moisture Content (VMC) versus depth over time. The Neutron Probe control unit was placed on top of the NP Aluminium access tube and the probe was lowered into the tube. The probe works by emitting a spherical cloud of neutrons, which interact with the surrounding soil particles and moisture. As the soil moisture content determines the diameter of the cloud (i.e., the dryer the soil, the larger the diameter), the device can be calibrated to estimate the soil moisture content at various depths using a calibration equation. This calibration equation was developed by collecting several soil samples within or close to the NP access tube and directly measuring the moisture content in the laboratory and then correlating these results with the Neutron Probe readings (NP).

\subsection{Ground and footing movement monitoring}

Magnetic extensometers were used to monitor the ground movement at different depths of a pre-drilled borehole, located adjacent to the NP access tube (see Fig). As shown in Fig. 5, the extensometers contain three sets of spider magnets attached to a collapsible pipe (the M.Ex access tube) to allow for ground movement. The legs of the magnets were held together using temporary ties before installation. After the instrument was lowered into position (in the borehole), the ties were removed and the legs were allowed to expand and penetrate / anchor into the surrounding soil. The location of the three spider magnets allows three soil layers to be evaluated for changes in thickness (i.e., swell and/or shrinkage at depth). The magnets were installed at depths of $0.679 \mathrm{~m}$, $1.726 \mathrm{~m}$ and $2.722 \mathrm{~m}$, thus creating three layers of 0.679 $\mathrm{m}, 1.047 \mathrm{~m}$ and $0.996 \mathrm{~m}$ thickness. 


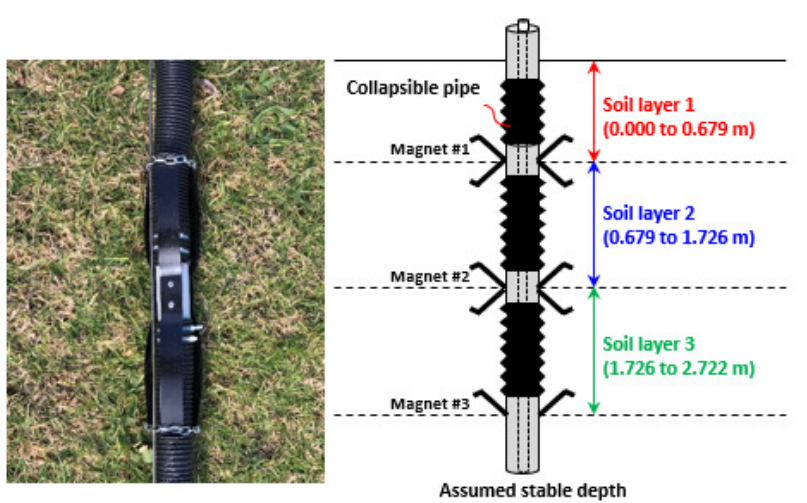

Fig. 5. Image and schematic diagram of the magnetic extensometers on a collapsible pipe.

It was assumed that there would be negligible movement below the expected depth of seasonal movement (according to the Australian Standard [19]). Thus, the bottom magnet at a depth of $2.722 \mathrm{~m}$ was taken as the datum. By placing a paving block (GL) next to the top of the extensometer, the total movement between the ground surface and the datum magnet was able to be calculated, which provided total ground movement at the surface. Moreover, a digital level was used to obtain vertical measurements for each concrete paver and the two mini-pile groups.

\section{$5 \quad$ Observations and results}

\subsection{Soil moisture and suction changes}

Monthly VMC measurements were recorded at certain regular depths using the NP counts and calibration equation. The variation in VMC was shown to substantially decrease with depth (Fig. 6), which reflected the local climate condition. Climate data was collected from the nearest weather station (Essendon airport, $8 \mathrm{~km}$ away from Braybrook) and has been presented in Fig. 7 along with fluctuations of soil VMC at various depths. This simple qualitative analysis indicates that changes in VMC of the upper soil layers are consistent with the weather events. Daily rainfall and relative humidity are positively associated with soil water content and conversely, evaporation and temperature are negatively associated. After rainfall events, the gradients of the VMC profiles increased markedly whereas, after a series of high daily temperature with no rainfall event, the gradients of the VMC profiles decreased. However, the soil moisture in the deeper layer was relatively unaffected by climate, when the error margin of the NP readings and the calibration line $\left(\mathrm{R}^{2}=0.82\right)$ are taken into account. In other words, an equilibrium moisture content was reached below the depth of about $1.5 \mathrm{~m}$, where the climate had less of an impact. The equilibrity between the moisture content and the climate might occur at shallower depths if a large foundation was placed on the surface which is capable of neglecting edge effects [22].

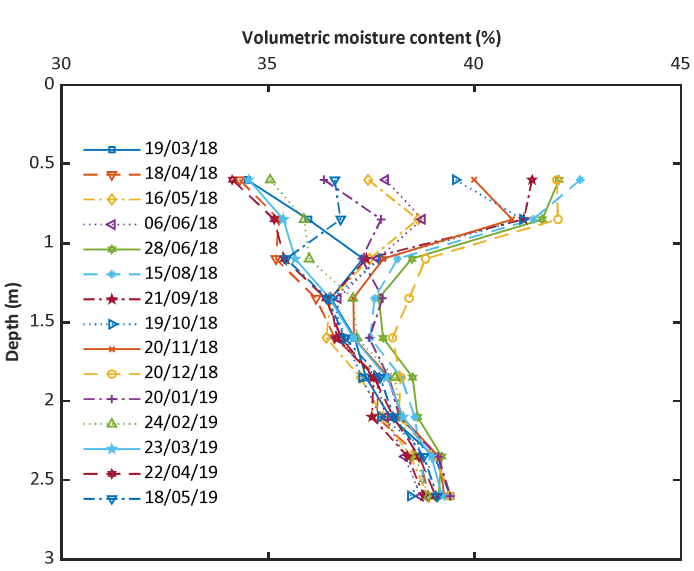

Fig. 6. VMC variation vs. depth for the experimental site at Braybrook over a 14-month period.

Soil moisture measurements were converted to total suction using the SWCC of a nearby test site [20] that has very similar clay mineralogy. Fig. 8 presents the wet and dry extreme suction profiles for the Braybrook site, which is also compared with the design suction change envelopes adopted in the Australian Standard [19]. At a depth of $0.6 \mathrm{~m}$, the measured change in suction was 0.52 $\mathrm{pF}$. Also, the recorded suction change at depth 2 to $2.6 \mathrm{~m}$ of approx. $0.05 \mathrm{pF}$ indicates that the adjacent trees are actually contributing to the moisture change at depth.
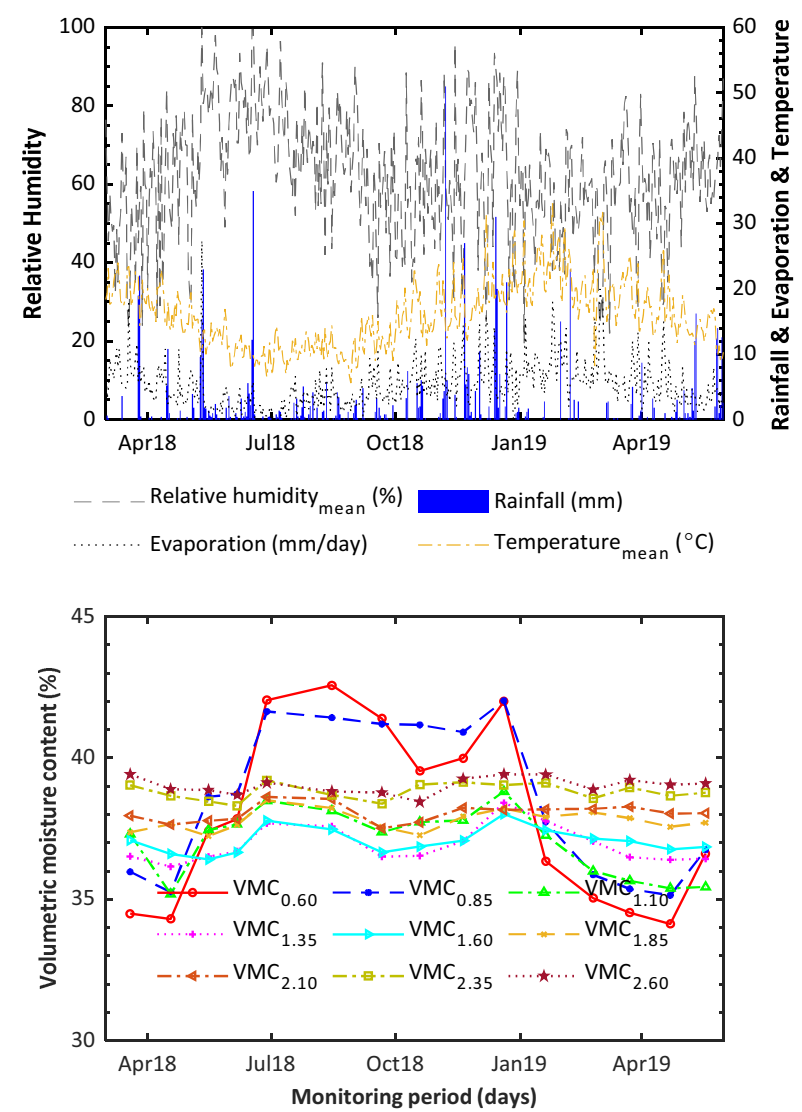

Fig. 7. Daily climate data and VMC at various depths vs. time. 


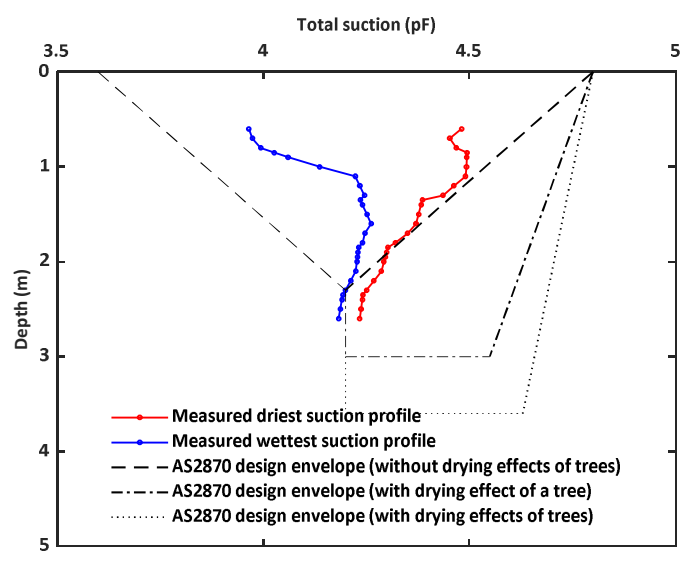

Fig. 8. Wet and dry extreme suction profiles measured for the Braybrook experimental test site between Mar 2018 and May 2019 vs. design suction envelopes from AS2870 (2011).

\subsection{Soil and footing movements}

To capture the effect of moisture content changes on the subsequent soil response, ground movements at different depths were recorded via the extensometer using the spider magnets. The total ground movements (or changes in layer thickness) for the three soil layers separated by the spider magnets correlated well with the moisture contents, which is presented in Fig. 9. Layers 1, 2 and 3 individually experienced movements of 19, 16 and $5 \mathrm{~mm}$ respectively, which yielded a total surface movement of $30 \mathrm{~mm}$. As shown in Fig. 10, this measured soil movement at different depths corresponds well to the predicted characteristic ground movement $\left(\mathrm{y}_{\mathrm{s}}\right)$ used in Australian Standard [19] based on $\mathrm{I}_{\mathrm{ss}}$ values and the site suction profile.

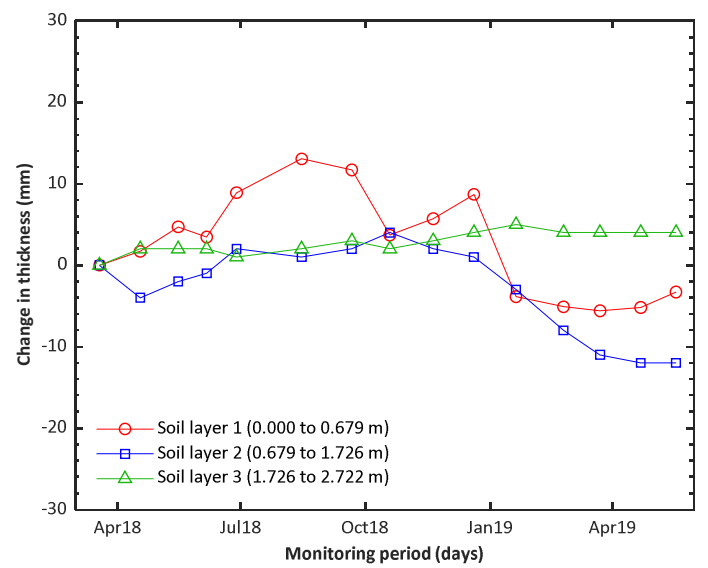

Fig. 9. Incremental ground movement over time for each soil layer based on the magnetic extensometers.

The total surface movement, measured via the extensometers and spider magnets, also compared well with those recorded for the concrete pavers using the digital level (Fig. 11). Although the total ground movement for each concrete paver varied slightly (i.e. between $30 \mathrm{~mm}$ and $36 \mathrm{~mm}$ ), the seasonal pattern of shrinkage and swelling was very similar. The digital level was also used to record movements at the top of the two braced mini-pile footing systems in order to evaluate their efficiency against the expansive soil induced ground movement. As shown in Fig. 11, no significant difference has yet been observed between the deeper $(1600 \mathrm{~mm})$ and the shallower $(1200 \mathrm{~mm})$ system as both recorded a total movement of $9 \mathrm{~mm}$. Besides, the trends of movement for both systems were almost identical.

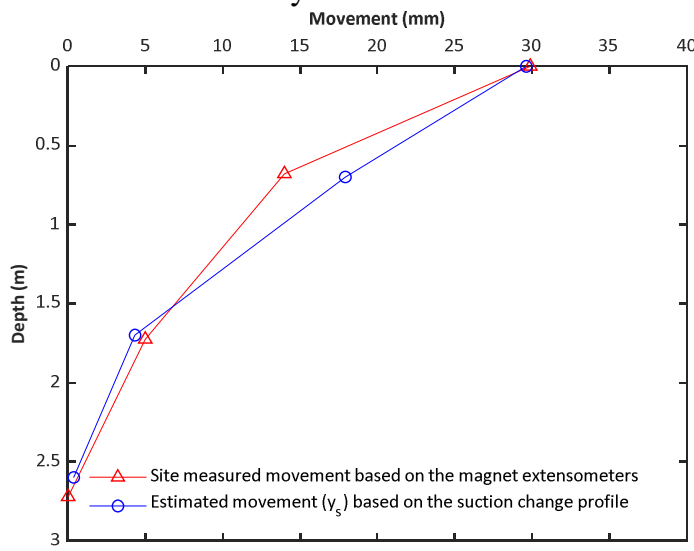

Fig. 10. Measured vs. predicted ground movement profiles.

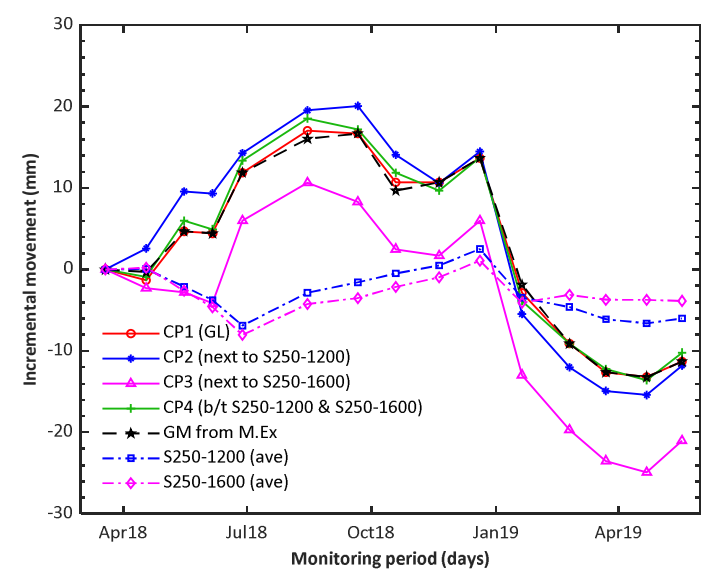

Fig. 11. All measured incremental ground movements for the experimental site and the two braced battered mini-pile footing systems.

\section{Discussion and conclusions}

The field trial at the Braybrook expansive soil site has demonstrated that this new driven battered steel minipile group footing system has the ability to significantly reduce moisture-change induced ground movements. We observed that the total actual movement of both footings was less than 30 per cent of the average ground movement recorded on this site. Thus, this new footing system reduced movement by nearly 70 per cent. No substantial difference in performance was noted between the two footing systems of different lengths, which may be related to moisture variations at the depth they are located at. The deeper and shallower footing systems 
experienced a moisture content change of approx. 4 and 2 per cent, respectively.

Based on the monitored soil moisture profile vs. depth, we also found that the shallower the depth, the more the VMC was likely to be affected by climate change. This is consistent with other studies [7, 23, 24]; however, more soil samples need to be collected to increase the accuracy of the calibration line. The more significant changes in VMC at shallower levels corresponded to a high suction change of $0.52 \mathrm{pF}$ near the surface of an open area. This value may decrease by placing a cover of large size on the ground surface. The Braybrook suction profile also recorded a suction change of $0.05 \mathrm{pF}$ at depth. Similar magnitudes have been recorded in other research and the value of suction at depth is likely to be attributable to the adjacent trees [19, 25]. These trees are located at a lateral distance of fewer than 1.5 times the height of the tree from the instrumentation, thus are suspected to increase the active depth [15]. The change in suction is associated with an average ground movement of $33 \mathrm{~mm}$, which falls within the normal expected range for this soil profile over such a short period [20]. The most considerable portion of this movement, approx. 83 per cent, occurred in the depth range of 0 to $1.726 \mathrm{~m}$. This is well-matched with a wide range of soil moisture and suction variation measured through the upper layers.

To summarize, as part of an ongoing research project, an experimental field trial was conducted to detect moisture profile, suction profile, ground movements, as well as the performance of a new driven battered mini-pile group footing system in a highly expansive site. Having confirmed the ability of this innovative system to combat the potential seasonal ground movement of expansive soils, our results have provided insight into the way the system actually works. Therefore, they can be used as a benchmark to validate numerical models that simulate the footing behaviour in this type of expansive clays.

\section{Acknowledgments}

This research was funded by Australian Research Council Linkage scheme (project ID LP160100828). In addition, the authors acknowledge the financial and in-kind support provided by Surefoot Pandoe Pty Ltd.

\section{References}

1. J. Christodoulias, J. Earth. Sci. Clim. Change 6, 5 (2015)

2. D.E. Jones Jr, W.G. Holtz, Civil Eng. 43, 8 (1973)

3. A.A. Al-Rawas, M.F. Goosen, Expansive soils: recent advances in characterization and treatment (Taylor \& Francis, 2006)

4. S.L. Hilbrich, T. Scullion, Design considerations for flexible pavement widening (Texas A \& M University System, 2007)

5. Y.E. Mohamedzein, M.G. Mohamed, A.M. El Sharief, Comput. Geotech. 24, 3 (1999)
6. J.D. Nelson, E.G. Thompson, R.W. Schaut, K.C. Chao, D.D. Overton, J.S. Dunham-Friel, J. Geotech. Geoenviron. 138, 8 (2011)

7. J.D. Nelson, Expansive soils: problems and practice in foundation and pavement engineering (New York: Wiley, 1992)

8. J.D. Nelson, K.C. Chao, D.D. Overton, and E.J. Nelson, Foundation engineering for expansive soils (New York: Wiley, 2015)

9. A. Mehdizadeh, M.M. Disfani, Ch.F. Tsang, G.A. Narsilio, R. Evans, E. Gad, Performance of a new driven battered micropiles system in sand

10. M.M. Disfani, R. Evans, E. Gad, A. Mehdizadeh, W. Jennings, Aust. Geomech. J. 53, 2 (2018)

11. A. Mehdizadeh, M.M. Disfani, R. Evans, E. Gad, A. Escobar, W. Jennings, Static load testing of concrete free reticulated micropiles system (ISC'5, 2016)

12. K.H. Northcote, Atlas of Australian soils: explanatory data for Sheet 2: Melbourne-Tasmania area. (C.S.I.R.O. and Melbourne University Press, 1962)

13. A. Mann, The identification of road sections in Victoria displaying roughness caused by expansive soils (Swinburne University of Technology, 2003)

14. K. McManus, R. Brown, Rehabilitation of Damaged Houses Founded on Expansive Soils Using Moisture Recharge (7th Australia New Zealand Conference on Geomechanics, 1996)

15. D.W. Cameron, P.F. Walsh, Damage to buildings on clay soils (Australian Council of National Trusts, 1984)

16. R.V. Mezzatesta, M. Verrochi, The performance of lightly loaded structures on expansive clay soils (Swinburne University of Technology, 1992)

17. H.B. Seed, R. Lundgren, Journal of the soil mechanics and foundations division, 88, 3 (1962)

18. A. Williams, J. South Afr. Inst. Civ. Eng. 5, 6 (1958)

19. AS2870 Residential slabs and footings (Standards Association of Australia, 2011)

20. A. Karunarathne, S. Sivaner, E. Gad, M.M. Disfani, P. Rajeev, J. Wilson, J. Li, Aust. Geomech. J. 49, 2 (2014)

21. Maps-Earth Resources Publications, http://earthresources.efirst.com.au/categories.asp?cI $\mathrm{D}=58$ (accessed Sep 2019)

22. J.D. Nelson, D.D. Overton, and D.B. Durkee, Expansive clay soils and vegetative influence on shallow foundations (2001)

23. S.I. Seneviratne, T. Corti, E.L. Davin, M. Hirschi, E.B. Jaeger, I. Lehner, B. Orlowsky, A.J. Teuling, Earth Sci. Rev. 99, 3 (2010)

24. A.J. Teuling, P.A. Troch, Geophys. Res. Lett. 32, 5 (2005)

25. D. Cameron, Unsaturated Soil Concepts and Their Application in Geotechnical Practice (Springer, 2001) 